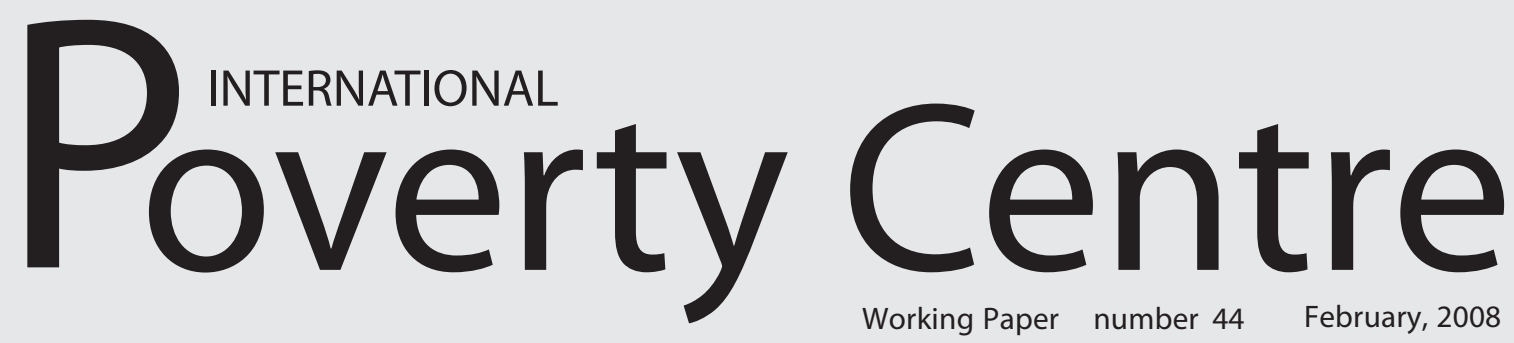

The International Poverty Centre is jointly supported by the Brazilian Institute for Applied Economic Research (IPEA) and the Bureau for Development Policy, United Nations Development Programme, New York.

\title{
DO CHANGES IN THE LABOUR MARKET TAKE FAMILIES OUT OF POVERTY? DETERMINANTS OF EXITING POVERTY IN
} BRAZILIAN METROPOLITAN REGIONS

\author{
Ana Flávia Machado \\ CEDEPLAR/UFMG and \\ International Poverty Centre
}

and

Rafael Perez Ribas

International Poverty Centre 


\title{
Copyright $(2008$
}

International Poverty Centre

United Nations Development Programme

\author{
International Poverty Centre \\ SBS - Ed. BNDES, $10^{\circ}$ andar \\ 70076900 Brasilia DF \\ Brazil \\ povertycentre@undp-povertycentre.org \\ www.undp-povertycentre.org \\ Telephone +55 6121055000 \\ Fax +556121055001
}

\section{Rights and Permissions}

All rights reserved.

The text and data in this publication may be reproduced as long as the source is cited.

Reproductions for commercial purposes are forbidden.

The International Poverty Centre's Working Papers disseminate the findings of its work in progress to encourage the exchange of ideas about major development issues. The papers are signed by the authors and should be cited and referred to accordingly. The findings, interpretations, and conclusions expressed in this paper are entirely those of the authors. They do not necessarily represent the views of the International Poverty Centre, IPEA or the United Nations Development Programme (or its Administrator, Directors, or the countries they represent).

Working Papers are available online at http://www.undp-povertycentre.org and subscriptions can be requested by email to povertycentre@undp-povertycentre.org 


\title{
DO CHANGES IN THE LABOUR MARKET TAKE FAMILIES OUT OF POVERTY?
}

\author{
DETERMINANTS OF EXITING POVERTY IN BRAZILIAN METROPOLITAN REGIONS*
}

\author{
Ana Flávia Machado ${ }^{* *}$ and Rafael Perez Ribas***
}

\begin{abstract}
The objective of this Working Paper is to estimate the likelihood of the exit of households from poverty and identify the determinants of this transition, taking into consideration the length of time that households have spent in poverty. Our focus is to analyze whether short-term changes in the labour market affect the probability of exiting or remaining in poverty. We use the only panel data that are available in Brazil for carrying out this kind of analysis: the Monthly Employment Survey (PME), which was conducted from March 2002 to May 2007. However, since this survey follows households for a very short period of time, we had to adopt estimation techniques that control for cases of right- and left-censoring. The most important results in this Working Paper are: 1) the longer the spell of poverty, the lower the probability of exiting it; 2 ) households that entered into poverty with zero income (namely, their poverty income gap was equal to one) are not those with the lowest probability of exiting this condition; 3 ) changes in the unemployment rate of household members do not directly affect the duration of the household's poverty; and 4) the increase of the average wage of informal workers has a significant, positive effect on the probability of the exit of poor households from poverty.
\end{abstract}

Keywords: Duration of poverty spell; Poverty exit; Labour market; Survival models for left-censored data.

JEL Classification: C41, I32, J64, R23

\footnotetext{
* The authors would like to thank the external peer reviewers of this Working Paper, Paulo Picchetti of the São Paulo School of Economics of the Getúlio Vargas Foundation (EESP/FGV) and Fábio Monteiro Vaz of the Institute of Applied Economic Research (IPEA), and the internal peer reviewer, Guilherme Issamu Hirata, IPC researcher, as well as Marcelo Neri of the Center for Social Policies of the Getúlio Vargas Foundation (CPS/FGV), for their helpful suggestions and comments. However, remaining errors and omissions are the sole responsibility of the authors. The syntax used in this paper is available for use by any interested party. Requests should be addressed to the following addresses: afmachad@cedeplar.ufmg.br and rafael.ribas@undp-povertycentre.org.

** CEDEPLAR/UFMG and IPC.

*** International Poverty Centre.
} 


\section{INTRODUCTION}

The reasons that a family remains in poverty are closely associated with the determinants of falling into this condition. Some households might leave poverty only temporarily while others might escape from it permanently. But a third group of households might remain chronically poor if they continue to have insufficient resources for a long period of time. Many studies have shown that the longer that a household or individual remains in poverty, the greater are the chances of permanence in that condition (Iceland, 1997b; Stevens, 1999; Dmitri, 2000; McKernan and Ratcliffe, 2003; Hussain, 2002).

This Working Paper seeks to estimate the probability of households moving out of poverty and the determinants of this transition, taking into account the length of time that they have been in poverty. Our main hypothesis is that the longer the period of poverty, the lower the probability of escaping from it. In other words, the actual duration in the condition helps determine its chronic nature.

On the supply side, household characteristics are the critical determinants of leaving poverty. However, on the demand side, we are interested in discovering whether changes in the labour market, such as fluctuations in the unemployment rate and the average wage, have any effect on the duration of households in poverty. Thus, this Working Paper has the specific aim of evaluating whether changes in aggregate demand are capable of removing households from poverty.

In Brazil, the only household survey that allows carrying out this kind of analysis with a representative sample is the Monthly Employment Survey (PME, Pesquisa Mensal de Emprego). The PME is a rotating panel that observes the same household for four consecutive months and, after an eight-month interval, observes it consecutively for four more months. After a total of eight monthly interviews, the household leaves the sample permanently.

Unfortunately, the period of 16 months between the first interview and the last is not long enough to observe the length of time that a household will remain in poverty. This short duration results in a high number of censored observations in our duration analysis. However, this survey format is considered appropriate for analyzing transitions and the effects of fluctuations in aggregate demand, because its monthly design allows investigation of shortterm changes. If annual data were used, a series of events that took place throughout the course of a year would be neglected. In our case, we decided to use the PME for the period running from March 2002 to May 2007.

Another of PME's limitations is its questionnaire, which is addressed exclusively to the analysis of the labour market. Thus, this survey includes only labour earnings and does not take into account other income sources such as pensions, unemployment insurance, rents, investment earnings, and private and public transfers. To deal with this problem of underestimating household income and, consequently, overestimating poverty, we adapted the method proposed by Elbers, Lanjouw and Lanjouw (2003) to impute the non-labour income of households.

In regression analysis, we have excluded neither the right-censored cases (when the movement of households out of poverty was not observed) nor the left-censored cases (when the entry of households into poverty was not observed). In the former case, the use of conventional survival models provides a method to treat this problem. But the latter case is 
not so simple because a left-censored sample can introduce bias into the analysis. However, the omission of such data provides a stronger bias than their inclusion because it would systematically exclude people who are in the midst of a long period of poverty (Iceland, 1997a).

In order to reduce this possible bias, we make use of survival models estimated by maximum likelihood, taking into account the probability of moving into poverty, and we thus consider left-censoring as a problem of initial condition (Ridder, 1984). These models, however, are based on a stationarity assumption - that is, the conditional probability of moving into poverty is assumed to be constant (D'Addio and Rosholm, 2002).

The results indicate that the longer the poverty spell of a household, the lower its probability of leaving this condition, especially from the second month of poverty onwards. Among the household characteristics, the presence of, at least, one elderly person has the strongest effect on the probability of exiting poverty, as opposed to remaining in this situation. It increases the chances of exit by more than 20 per cent. Regarding the situation in which a household moves out poverty, we found that, on average, the farther its per capita income is below the poverty line, the lower the probability of its exit from poverty. Nevertheless, this effect is convex, which implies that households with no income or the lowest level of income are not the ones with the greatest probability of staying in poverty.

Finally, regarding changes in the labour market, we found that the movement of workers from the industrial and commercial sectors to the service sector in metropolitan regions significantly reduces the length of time that households spend in poverty. Another result is that changes in the unemployment rate have not had a direct effect on keeping households in, or taking them out of, poverty. But variations in the average wage have had a significant impact.

Apart from this introduction, this Working Paper is divided into six sections. In the second section, there is a summary of the literature on the dynamics and duration of poverty. The third section provides a brief description of how we imputed non-labour income in the PME. The fourth section presents the framework of the models and the estimation methods used in this paper. In the fifth section we describe our database. The sixth section presents the results of the duration models. In the final section, we present some conclusions based on our results.

\section{DURATION IN AND MOBILITY OUT OF POVERTY: A BRIEF REVIEW OF THE LITERATURE}

There are several studies in the literature that estimate the duration of poverty and the determinants of moving into and out of this condition. However, most of them were carried out in developed countries, where more panels of data are available. So far, few studies have been carried out in developing countries such as Brazil.

As far as developed countries are concerned, the majority of the studies have been conducted in the United States, based on the Panel Study of Income Dynamics (PSID), a panel that has a continuous series going back to 1967. For instance, Duncan (1983) and Duncan and Rodgers (1991) estimate the number of years that households remain in poverty but without taking into consideration any of the problems related to censored data.

When the observations are made over a short period of time, this procedure can lead to the underestimation of the time spent in poverty. For example, at the time of its final interview, 
a household might be on the brink of a long period in poverty. Similarly, at the time of the first interview, a household might already have had an extended history of income deprivation that would remain unrecorded.

Bane and Ellwood's 1986) study, which also uses the PSID data, goes beyond its predecessors by using an approach to duration that takes into account cases of rightcensoring, i.e., when the exit from poverty is not observed. However, this work is restricted to the analysis of consecutive observations of a single process, which is called 'simple spell of duration analysis'.

Stevens $(1994,1999)$ improves on Bane and Ellwood's study since he estimates the hazard ratios and their determinants for multiple poverty spells, and also increases the length of the panel series by six years. Comparing simple and multiple spells models, the author concluded that the former tend to overestimate the rate of exit from poverty. Stevens' results indicate that the probability of remaining in poverty increased during the decade from 1970 to 1980 , principally in households headed by women. In addition, moving out of poverty did not imply remaining out of this condition. The author mentions that 50 per cent of the people who escaped poverty returned in less than five years, and the probability of returning has been increasing in the case of households headed by white women.

The study made by Iceland (1997b) also uses the PSID to estimate the chances of leaving poverty, as opposed to remaining in it. He attempts to relate aspects of aggregate demand to this event by using covariates that express the changes in the U.S. urban labour market from 1970 to 1985 . This author uses annual variations in the proportions of employees working in the industrial, service and commercial sectors in order to obtain the effect of industrial reorganization, which, initially, reduces the number of jobs in the industrial sector.

Iceland considers the possibility of a mismatch between individual skills and job requirements by examining the annual variation in the percentage of employees with more than 11 years of study, i.e., high school level or higher. It is important to emphasize that the author does not omit left-censored observations, since he holds that such a procedure would introduce a strong bias into the analysis. The solution adopted for this problem, described in Iceland (1997a), was to include a dummy to identify the censored cases in the regression analysis.

Iceland's results indicate that spatial segregation does not produce any significant effect on moving out of poverty. Nevertheless, urban de-industrialization tends to favour Whites more than Blacks with regard to transitions out of poverty. But in the areas where there is a significant expansion of the commercial sector, the chances of Blacks exiting poverty were greater than in industrialized areas, where they were usually employed as blue-collar workers. The skill-mismatching hypothesis is not robust for Whites but is robust for Blacks, especially in the service sector.

Instead of working with annual data, Ruggles and Williams (1987) and McKernan and Ratcliffe (2003) use the Survey of Income and Program Participation (SIPP), which also covers the United States, in order to investigate the determinants of entering into and moving out of poverty on a monthly basis. According to these authors, monthly data allow a more accurate estimate of the relationship between events and mobility. Ruggles and Williams argue that associating an annual change in a household situation with an event that took place at some moment during that same twelve-month interval is more difficult than associating a monthly change with an event that took place in that same month or in the one immediately preceding it. 
McKernan and Ratcliffe use the same strategy of estimation put forward by Iceland (1997a) and, in the same way as Ruggles and Williams, they indicate that the events of moving into and out of poverty are associated more with changes in occupation and income than with changes in household structure and composition.

Hussain (2002) used data from Denmark to analyze simple and multiple poverty spells and, like Stevens, incorporated treatment for censored data and for non-observed heterogeneity. He showed for the period from 1976 to 1997 that the levels of schooling and the number of hours of work increased the probability of leaving poverty and reduced the probability of returning to this state. He also found that children and a single-parent household head reduced the probability of households moving out of poverty and increased the probability of returning to it. The author points out that, with regard to aggregate demand, the lower the unemployment rate, the lower the average time spent in poverty.

Cappelari and Jenkins (2002) used nine waves of the British Household Panel Survey (BHPS) from 1991 to 1999 to estimate a Markovian model for entry into and exit from poverty that does not take into account the previous duration of each state. However, they found that being poor had a significant effect on the probability of remaining in this condition. This is known as 'genuine state dependence'. Their results also indicate that the degree of persistence in poverty increases in accordance with the age of the household head and is higher when the head is male, unemployed, Pakistani or Bengali.

Dmitri (2000) used a conventional duration model for Russia and found that single mothers and the unemployed were the groups most vulnerable to remaining in poverty. In spite of the fact that rural poverty was more severe than urban poverty, the author also found that rural households had a greater probability of exiting poverty than households in metropolitan areas. However, this particular result was not corroborated in the study carried out by Denisova (2007).

Bigsten and Shimeles (2003) found results similar to Dmitri's in Ethiopia, showing that poverty is more persistent in urban than in rural areas. They also point out that in rural areas, the size of the household's cultivated area, the price of the crops that it grew and its access to local markets, as well as the educational level of the household head, are associated with a significant reduction in its vulnerability to poverty.

For Argentina between 1991 and 2003, Beccaria and Maurízio (2006) analyzed the probability of entering into poverty and of remaining in that situation. They concluded that a higher rate of entry into poverty and a lower probability of leaving this state are almost completely explained by negative shocks in the labour market, such as increased unemployment and wage reductions. According to these authors, the events related to demographic factors are of little relevance.

In Brazil, there are a few studies of poverty duration. The study by Barros, Mendonça and Neri (1995) was one of the first to investigate this topic. They also used the PME panel but made only a descriptive analysis. Their analysis intended neither to investigate the determinants of poverty spells nor control for the problem of censoring.

However, they found interesting results, concluding that each month 15 per cent of all households cross the poverty line by the value of one minimum wage in either direction. They found that a large proportion of poverty spells are of very short duration, and that poor 
households experiencing longer poverty spell have a lower probability of escaping from poverty. Finally, they pointed out that among the non-poor, those with past experience in poverty have a higher probability of returning to this state.

There are also two studies that estimate the probability of entry into and exit from poverty, using a transition model similar to the one proposed by Cappelari and Jenkins. These studies were carried out by Machado, Ribas and Penido (2007) and Ribas and Machado (2007). The first analyzed monthly transitions by using the PME for 2004. It concluded that being in the informal sector has an ambiguous effect on mobility because it contributes both to exiting poverty and increasing the vulnerability to poverty. Moreover, the longer the duration that a worker is employed, the lower the probability of his entering into poverty.

This study, as well as Barros, Mendonça and Neri's, assumed a monetary poverty definition that does not take account, however, of non-labour sources of income. Therefore, the poverty rates in both studies are well overestimated and the poverty dynamics are actually exclusively related to changes in labour conditions.

The second study mentioned above, by Ribas and Machado, is a cohort analysis of mobility between two-year intervals that used data from the Brazilian National Household Survey (PNAD, Pesquisa Nacional por Amostra de Domicilios). Ribas and Machado point out that older people, as well as those who complete elementary school, have a lower probability of falling into poverty or remaining in that state. They also found that gender and race have an effect just on the permanence in poverty (with a longer permanence among Blacks and women), but not on the transition into it.

In summary, we can conclude from this review that, first, the event of entry into poverty and permanence in this state are associated more with changes related to employment in the labour market than with factors of household structure and composition. Nevertheless, most of the studies that come to this conclusion might not have taken into account the endogeneity of income shocks in mobility models.

The second conclusion is that the omission of censored data, along with analysis based on simple intervals of duration, can underestimate the average time spent in poverty. However, it should be acknowledged that analysis based on multiple spells of duration is possible only when there is a panel with a large number of waves.

Finally, we point out that analysis of duration using annual data ignores a series of events that occur between the two yearly interviews. In fact, Iceland (2003) states that estimates based on annual data tend to overestimate the time spent in poverty. He shows, for example, that almost 80 per cent of the poor in the United States observed between 1996 and 1999 remained in poverty for less than one year. Consequently, a very wide range of demographic groups do not spend any more than an average of six months in poverty.

\section{IMPUTATION OF NON-LABOUR INCOME IN THE PME}

Many studies of poverty consider a low per capita income to be a measure of the inability of a household to satisfy its basic necessities. Household income comes from various sources, such as labour, interest, rent, pensions, and private and government transfers, but it is derived predominantly from labour (Barros, Cury and Ulyssea, 2007). 
As a result of its specific interest in investigating the urban Brazilian labour market, the PME provides information only about income from work. For this reason, we have adapted the technique proposed by Elbers, Lanjouw and Lanjouw (2003) to impute non-labour earnings to the households surveyed by PME by using data from PNAD.

Elbers, Lanjouw and Lanjouw's method consists in estimating a variable of interest based on common covariates of two distinct databases. This technique is usually employed in drawing up 'poverty maps'. In such cases, the variable of household income or consumption is estimated by means of a survey, which is not representative at the municipal level, but this estimation is attributed to the census data. Despite the questions about the reliability of this technique, ${ }^{1}$ there are two advantages in our case that make the imputation consistent. The first advantage lies in the similarity between the questionnaires used by PNAD and PME. The second advantage lies in the fact that, in metropolitan areas, the size and representativeness of both samples are almost identical.

In order to attribute non-labour income to households, we first limited the PNAD's sample to those metropolitan regions that are also covered in the PME, i.e., Recife, Salvador, Belo Horizonte, Rio de Janeiro, São Paulo and Porto Alegre. Since retirement benefits, other pensions, and other earnings, such as interest, rent, transfers and donations, have distinct determinants, we decided to estimate a model for each type of income. We thus have four models: retirement pensions received by individuals; other pensions received by individuals; other incomes received by 'poorer households'; and other incomes received by 'richer households'.

In this case, the division between 'poorer households' and 'richer households' is based on per capita labour income and is set at the sixth decile of the income distribution. This division is caused by the diverse nature of the other categories of income. For poor households, 'other incomes' come predominantly from cash transfer programmes, such as the Bolsa Familia (Family Allowance) and donations. For richer households, the 'other incomes' are derived more from rent and interest.

The four income models were estimated from PNAD based on Heckman's (1979) two-step method. In the first step, we estimated the probability of receiving a particular type of nonlabour income using a probit model. Then we estimated the inverse of the Mill's ratio. In the second step, we estimated the values of earnings according to a subset of variables from the first step and the inverse of the Mill's ratio. The covariates in both the first and the second steps were selected by using a stepwise estimation, in which the instrumental variables, which are required for a consistent estimation, were selected. ${ }^{2}$ Therefore, 96 equations were estimated (combining four income sources, six metropolitan regions and four years, from 2002 to 2005).

Once the probability of receiving sources of non-labour income and their amounts had been estimated, the coefficients and standard errors were exported to the PME data. It is important to emphasize that the standard errors of the earnings regressions were also parameterized by using the stepwise estimation - that is, we assumed that the errors were heteroscedastic. Thus, the task of imputation basically consists of taking the vectors of coefficients estimated using PNAD and relating them to characteristics of individuals and households in the PME.

In addition, we were careful with regard to the difference in periodicity between the two surveys. The estimates from PNAD of a particular year were attributed to the PME of the same year, beginning on the month in which the nominal minimum wage had been changed (which 
usually occurs in April or May), and similarly for the PME from the following year up to the month of the next minimum wage readjustment.

Since the available PME series is wider than that of PNAD, the estimates of PNAD 2005, in particular, allowed for the imputation of values to the PME until May 2007. In addition, for all years, the September values of PNAD were deflated according to the value of the adjusted National Consumer Price Index (INPC) ${ }^{3}$ (Corseuil and Foguel, 2002), in order to make them equivalent to the monthly values of the PME. Further details about the process of imputation can be found in Appendix I of this Working Paper.

In order to demonstrate the consistency of the imputation process, we provide in Table A1 of the Annex descriptive statistics for the different sources of income observed in PNAD and attributed to the PME. In that table, which refers to September 2005, we found that there are no significant differences between the statistics.

\section{EMPIRICAL FRAMEWORK-SURVIVAL MODELS}

In order to estimate the duration of poverty in Brazilian metropolitan areas between 2002 and 2007, we analyzed the periods of time spent in this state and the determinants of this duration. Our hypothesis is that household structure and composition, the poverty income gap and fluctuations in aggregate demand are the main determinants of households' exit from poverty.

The well-known survival models are the most suitable for estimating the time that a household is likely to spend in poverty. The so-called 'failure' takes place when the process of moving out of that condition occurs. Using these models, one can estimate the probability of remaining in poverty beyond a specific period of time $t$, called the survival function. It can be expressed as $S(t)=P(T \geq t)$ or $S(t)=1-F(t)$, where $F(t)$ represents the accumulated distribution of cases from the time zero to the time $t$.

The probability of a failure taking place, that is, the probability of exiting poverty at a specific moment, which is also called the hazard function or rate, can be described on the basis of the difference between the survival function at two moments, $S\left(t_{1}\right)-S\left(t_{2}\right)$, weighted by the length of that interval:

$$
h(t)=\frac{S\left(t_{1}\right)-S\left(t_{2}\right)}{\left(t_{2}-t_{1}\right) S\left(t_{2}\right)} .
$$

Also, if $f(t)$ represents the density function of cases according to survival time, the hazard function can be expressed as:

$$
h(t)=\frac{f(t)}{S(t)}=\frac{f(t)}{1-F(t)},
$$

bearing in mind that $F(t)=\int_{0}^{t} f(s) d s$. 
In parametric models, the function $f(t \mid X)$ can take on various forms. In this Working Paper, we consider the Weibull, Gompertz, Log-logistic and Inverse Gaussian distributions. Unfortunately, due to the large number of left-censored cases, we were unable to carry out tests of adequacy of distributions, such as the Cox-Snell test, in order to find out which of them is the most appropriate. Therefore, we decided to estimate models that are based on different distributions in order to check the robustness of our results.

The density functions for each of the assumed distributions are described below:

$$
\begin{aligned}
& f(t \mid X)=\gamma \lambda t^{\gamma-1} \exp \left(-\lambda t^{\gamma}\right) \quad \text { Weibull } \\
& f(t \mid X)=\lambda \exp \left(x-\lambda \gamma^{-1}\left(e^{x}-1\right)\right) \quad \text { Gompertz } \\
& f(t \mid X)=\frac{\mu^{1 / \gamma} t^{1 / \gamma-1}}{\gamma\left(1+(\mu \cdot t)^{1 / \gamma}\right)^{2}} \quad \text { Log - logistic } \\
& f(t \mid X)=\frac{1}{\sqrt{2 \pi \gamma \cdot t^{3}}} \exp \left[-\frac{(t-\lambda)^{2}}{2 \gamma \lambda^{2} t}\right] \text { Inverse Gaussian, }
\end{aligned}
$$

where $\lambda=\exp \left(X^{\prime} \beta\right), \mu=\exp \left(-X^{\prime} \beta\right)$ and $\gamma$ and $\beta$ are parameters that define the format of the conditional distribution. ${ }^{4}$

The inverse Gaussian distribution, parameterized according to the Wiener process with absorption (namely, the process starts at some positive value and finishes whenever it hits zero) was also used in this paper. Wiener processes are normally used to calculate the distance between the beginning of the process and the state of absorption (Lancaster, 1982; Doksum and Høyland, 1992). Thus, it is assumed that the process of falling into poverty is heterogeneous and that distance determines the format of the hazard function. According to Aalen and Gjessing (2001), a long distance between the two points is associated with a rising hazard rate. An intermediate distance implies a hazard rate that rises and then falls, while a short distance indicates a falling hazard rate.

The density function calculated by the Wiener process with absorption has the following specifications:

$$
f(t \mid X)=\frac{c}{\sigma \sqrt{2 \pi \cdot t^{3}}} \exp \left[-\frac{(c-\eta \cdot t)^{2}}{2 \sigma^{2} t}\right]
$$

where $\eta=\exp \left(X^{\prime} \beta\right), \sigma$ and $\beta$ are the parameters that define the format of the conditional distribution and $c=\exp \left(Z^{\prime} \gamma\right)$ is the component that determines the distance between the points of entry and absorption, based on the vector $Z$ of characteristics and the vector $\gamma$ of coefficients. It should be noted that when $c=\sqrt{\gamma^{-1}}$ and $\eta=\sqrt{\gamma^{-1}} / \lambda$, function (2) becomes identical to the inverse Gaussian distribution in (1).

We believe that the Wiener process controls in part the effect of re-entry into poverty, which is not taken into account due to the limitations of the panel data that we use. In other words, in accordance with their specific characteristics, certain households enter poverty already liable to remain in this situation for a longer period than others. 
Iceland (1997a) argued that left-censoring is one of the main problems of poverty duration models. According to D'Addio and Rosholm (2002), duration models that control leftcensoring are rarely found in the literature ${ }^{5}$ because they are difficult to estimate. In addition, the general understanding is that left-censored observations do not contain relevant information that can be used empirically.

These authors also indicate that two solutions are usually adopted for the problem of leftcensoring. Either a very limiting assumption of stationarity is made or all left-censored observations are omitted. However, in situations where there is a relatively short period of observation and the proportion of censored cases is high, the information contained in those cases is critical.

Therefore, we decided to make the assumption of stationarity to compensate for not limiting the sample in any way. Adopting this assumption implies assuming that the conditional rate or probability of entry into poverty is constant. On this basis, we calculated the duration models by maximizing the likelihood function proposed by Amemiya (1999). When $n_{1}$ represents the number of left-censored cases and $n_{2}=n-n_{1}$ is the number of the remainder of cases, Amemiya's probability function consists of an equation with two separate parts, according to the type of sample, which are multiplied by the respective probability of whether the information is left-censored or not:

$$
L=\prod_{i=1}^{n_{1}}\left[\frac{S\left(t_{i} \mid X_{i}\right)}{E\left(T \mid X_{i}\right)} \frac{P_{0}\left(X_{i}\right)}{P_{0}\left(X_{i}\right)+P_{1}\left(X_{i}\right)}\right] \cdot \prod_{i=1}^{n_{2}}\left[\frac{e\left(\tau_{i} \mid X_{i}\right) h\left(t_{i} \mid X_{i}\right) S\left(t_{i} \mid X_{i}\right)}{P_{1}\left(X_{i}\right)} \frac{P_{1}\left(X_{i}\right)}{P_{0}\left(X_{i}\right)+P_{1}\left(X_{i}\right)}\right]
$$

In this function, $t_{i}$ is the total time that the case $i$ remains in the state and $\tau_{i}$ is the observed time of the case $i$ in the state. $E\left(T \mid X_{i}\right)$ represents the expected duration of the case $i$ and $e\left(\tau_{i} \mid X_{i}\right)$ is the rate of entry into the state at time $\tau_{i} . P_{0}\left(X_{i}\right)$ and $P_{1}\left(X_{i}\right)$ are the probabilities of being in the state at time 0 , before beginning the count, and at time 1 , at the beginning of the count, respectively. $X_{i}$ is the vector of the characteristics that determine the entry into and the permanence in the state under analysis.

If we assume a constant rate of entry into the condition, we can state that $e\left(\tau_{i} \mid X_{i}\right)=e\left(X_{i}\right), P_{0}\left(X_{i}\right)=e\left(X_{i}\right) E\left[T \mid X_{i}\right]$ and $P_{1}\left(X_{i}\right)=\tau_{1} e\left(X_{i}\right)$. Therefore, function (3) can be simplified to:

$$
L=\prod_{i=1}^{n}\left[\frac{h\left(t_{i} \mid X_{i}\right)^{d_{i}} S\left(t_{i} \mid X_{i}\right)}{E\left(T \mid X_{i}\right)+\tau_{1}}\right]
$$

where $d_{i}=\{0,1\}$ is an indicator of whether the observation is left-censored or not and $\tau_{1}$ denotes the observed duration from the first period onwards. ${ }^{6}$ 


\section{THE PME SAMPLE AND THE DESCRIPTION OF VARIABLES}

As mentioned previously, the data on poverty duration are taken from the PME (Pesquisa Mensal de Emprego - Monthly Employment Survey) that was conducted from March 2002 to May 2007. We took the poverty line for metropolitan regions calculated by the World Bank (2006) and deflated for the months in the PME.? Then, we classified as 'poor' households the ones whose per capita income was below this line. It is important to remember that household income includes all the types of income resulting from carrying out the imputation described earlier in this paper. In addition, those who declared themselves to be guests, domestic workers or their relatives were not included in the household composition.

In order to produce the database used specifically to analyze poverty duration, we used, first of all, the algorithm proposed by Ribas and Soares (2008) to put together the whole panel of individuals. Then, we identified those households in which at least one member was observed in more than one interview and separated them from those households in which all the members had left the sample. In other words, we considered a household to have undergone attrition when none of its members were observed subsequently in the sample.

Once the families that had been interviewed at least twice and had spent no less than one month in poverty had been identified, we counted the number of months each family had been in this state. This period was calculated according to the number of months between two consecutive observations. For instance, in the case of the household that had already fallen into poverty at the time of the fourth interview, remained in the same treated situation for the fifth interview (eight months afterwards) and had exited poverty by the time of the sixth interview, we assumed that it had been in deprivation for 10 months.

However, if this household had been observed to be out of poverty at the time of the fifth interview, we treated it as right-censored, because we did not know in what month it had actually left poverty. This same criterion of interpolation of periods was adopted for households whose attrition had occurred in a particular month of an interview, but had recovered one month later. It should also be mentioned that such cases were not completely excluded from the sample: they were treated as left-censored cases.

Table 1 presents the descriptive statistics for the selected variables used in the poverty duration model and shows that the average observed duration in poverty was 2.69 months. However, almost 45 per cent of the sample is right-censored, while about 46 per cent is leftcensored. We also found that São Paulo and Rio de Janeiro comprise, respectively, 38 per cent and 22 per cent of the sample.

The average percentage of working-age people (between 18 and 65 years of age) in poor households is 59 per cent. In addition, among households in poverty, 47 per cent have at least one child, 22 per cent have more than one child, 31 per cent have at least one adolescent, 20 per cent have more than one adolescent, and 17 per cent have at least one elderly member. Almost 57 per cent of poor households have at least one adult with elementary education. In 45 per cent of households, the head is white; and for a similar percentage, the head is single. Single women are the heads of 37 per cent of poor households. The average age of the household head in the sample is 46 years old and the average income gap for poor households is 51 per cent of the poverty line. 
TABLE 1

Descriptive Statistics of the Variables

\begin{tabular}{|c|c|c|c|c|c|}
\hline Variable & Mean & $\begin{array}{l}\text { Standard } \\
\text { Deviation }\end{array}$ & Variable & Mean & $\begin{array}{l}\text { Standard } \\
\text { Deviation }\end{array}$ \\
\hline Observed duration & 2.69268 & 0.011981 & Unmarried head & 0.45482 & 0.001510 \\
\hline Right censoring & 0.44832 & 0.001637 & Unmarried female head & 0.37072 & 0.001449 \\
\hline Left censoring & 0.46455 & 0.002313 & Head's age & 46.3144 & 0.049177 \\
\hline MA Recife & 0.11748 & 0.000854 & Presence of: & & \\
\hline MA Salvador & 0.09659 & 0.000703 & one child or more & 0.46791 & 0.001572 \\
\hline MA Belo Horizonte & 0.10125 & 0.000563 & two children or more & 0.21964 & 0.001296 \\
\hline MA Rio de Janeiro & 0.22308 & 0.001090 & one adolescent or more & 0.30931 & 0.001380 \\
\hline MA São Paulo & 0.38088 & 0.001414 & two adolescents or more & 0.20069 & 0.001153 \\
\hline MA Porto Alegre & 0.08072 & 0.000483 & one elderly person or more & 0.16691 & 0.001152 \\
\hline Poverty income gap & 0.51138 & 0.001115 & illiterate adult & 0.15381 & 0.001054 \\
\hline Poverty income gap squared & 0.39594 & 0.001281 & functionally illiterate adult & 0.35967 & 0.001448 \\
\hline Log of number of members & 1.10952 & 0.001921 & adult with elementary school & 0.56801 & 0.001505 \\
\hline Extended household & 0.05669 & 0.000640 & $\begin{array}{l}\text { at least two adults with } \\
\text { elementary school }\end{array}$ & 0.23310 & 0.001259 \\
\hline $\begin{array}{l}\text { Proportion of working- } \\
\text { age members }\end{array}$ & 0.58794 & 0.000871 & adult with high school & 0.32480 & 0.001450 \\
\hline White head & 0.45204 & 0.001588 & adult with college education & 0.03195 & 0.000572 \\
\hline Number of strata & 372 & & Number of observations & 165656 & \\
\hline Number of PSU & 80432 & & Universe of households & $6.90 \mathrm{E}+07$ & \\
\hline
\end{tabular}

Note: MA = Metropolitan Area; PSU = Primary Sample Unit.

Source: Own calculations based on PME 2002-2007.

Table 2 shows the size of the samples used in the estimates of the duration models. In the reduced sample, used to calculate just the effects of fixed variables, there is a similar number of observations that are only right-censored or only left-censored (approximately 30 per cent), while 16 per cent of the data is interval-censored. Based on these statistics, we concluded that the relative number and, most importantly, the absolute number of observations not censored is sufficient to estimate the effects of a poverty duration model using the PME data. In the expanded (split) sample, used to estimate the effects of fluctuations in aggregate demand, the number of right- and interval-censored observations increased and, as a result, the percentage of non-censored cases was reduced. Nonetheless, there was only a slight reduction in the absolute number of these cases.

The difference between the reduced sample and the split sample lies in the number of times that the same household appears in the database. In the first case, each household is represented by only one observation, which contains the total number of months that it was in poverty, censored or not, and the fixed variables that permanently characterize it. These fixed variables are generally those that represent the household's characteristics at the first time that it was observed in poverty. 
TABLE 2

Number of Observations

\begin{tabular}{lcc}
\hline Reduced Sample & & Per cent \\
Total observations & 165,656 & 24.48 \\
non-censored & 40,548 & 29.37 \\
right-censored & 48,653 & 29.95 \\
left-censored & 49,618 & 16.20 \\
$\quad$ interval-censored & 26,837 & Per cent \\
\hline Expanded (Split) Sample & & 12.35 \\
Total observations & 324,056 & 29.25 \\
$\quad$ non-censored & 40,036 & 14.57 \\
$\quad$ right-censored & 94,796 & 43.82 \\
$\quad$ left-censored & 47,227 & 141,997 \\
$\quad$ interval-censored & & \\
\hline
\end{tabular}

Source: Own calculations based on PME 2002-2007.

In the second case, each observation corresponds to a month that the household was in poverty. In other words, the same household can be repeatedly reported in the split sample. Each observation contains the number of months observed in poverty until that moment and the characteristics of the labour market in that month, as well as the same fixed variables from the previous sample. As a result of the expansion of data points, the observed number of households that do not last in poverty for the complete duration increases, and so does the number of right-censored cases.

The small reduction in the number of non-censored cases is due to the inclusion of lagged time-dependent variables so that we could analyze the quarterly variations in the labour market. Thus, the three first months of the survey (March, April and May, 2002) were omitted in the expanded sample.

\section{RESULTS}

\subsection{THE SLOPE OF THE PROBABILITY (HAZARD) FUNCTION FOR EXITING POVERTY}

As mentioned before, the analysis of poverty spells using the PME requires control of both right- and left-censoring. Before presenting the results of the parametric models that include this control, we present the Kaplan-Meyer function, but not including the left-censored cases (Graph 1). This non-parametric estimation simply allows us to perceive the survival function that arises out of the observed data.

At moment $t=0,100$ per cent of the sample is in poverty, which is an assumption of the survival analysis model. By the end of the first month, 60 per cent are still in poverty and by the end of the third month, 50 per cent. The sharp drop of the line in the first two months indicates the high probability of escaping from poverty in this period. The horizontal straight line that appears after the third month and continues until the tenth month represents the period of eight months between the fourth and fifth interviews of the households in the PME panel. 
GRAPH 1

Non-parametric (Kaplan-Meier) Estimation of the Poverty Duration Function

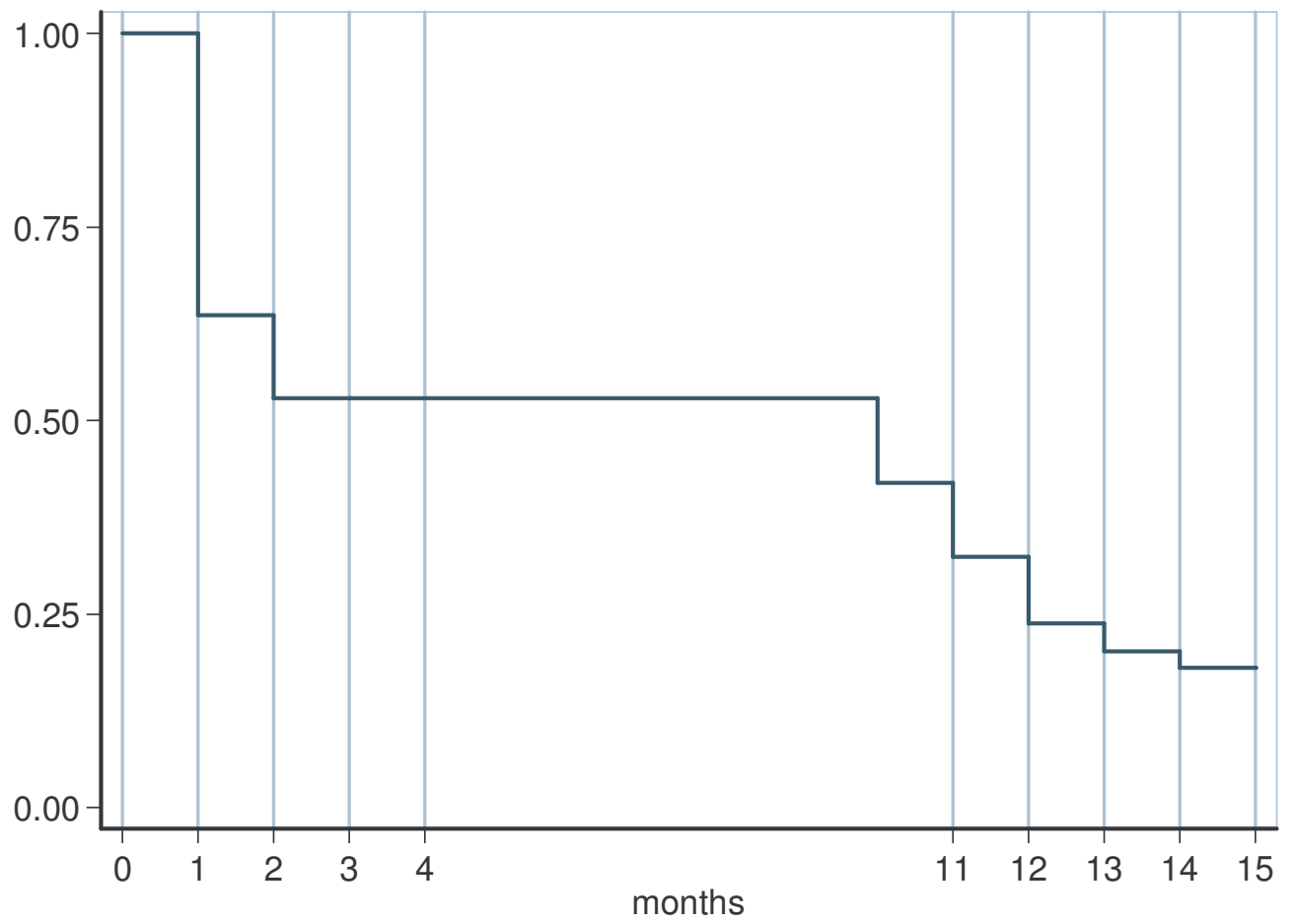

Source: Own elaboration based on PME 2002-2007.

From the tenth month onwards, we can see that some households move out of poverty, but at a much lower rate than in the first two months. Finally, the distance of the survival curve from the horizontal axis records the fact that there is a significant amount of right-censored data - that is, the presence of households that will remain in poverty for some time to come.

Without parameterization, the omission of left-censored cases and the lack of exit of households from poverty between the third and the tenth month result in a hazard function with a positive slope (Graph 2). In light of this evidence, we emphasize that it is necessary to use parametric models in order to estimate a more consistent hazard function that does not leave out censored cases.

In contrast to Graph 2, Graph 3 shows that all the parametric hazard functions based on the full sample have a negative slope from the second month of the poverty spells onwards. Therefore, the longer a household remains in poverty, the greater are its chances of staying there. With the exception of the Weibull model, it is observed that, after the tenth month, the average probability of leaving poverty is less than 20 per cent.

The inverse Gaussian function indicates the most critical condition. According to this model, the mean probability of exiting poverty in the first month is less than 40 per cent. After the third month, the probability drops to less than 10 per cent and, after the tenth month, it is almost zero. 
GRAPH 2

Non-parametric Estimation of the Probability (Hazard) Function of Exiting Poverty

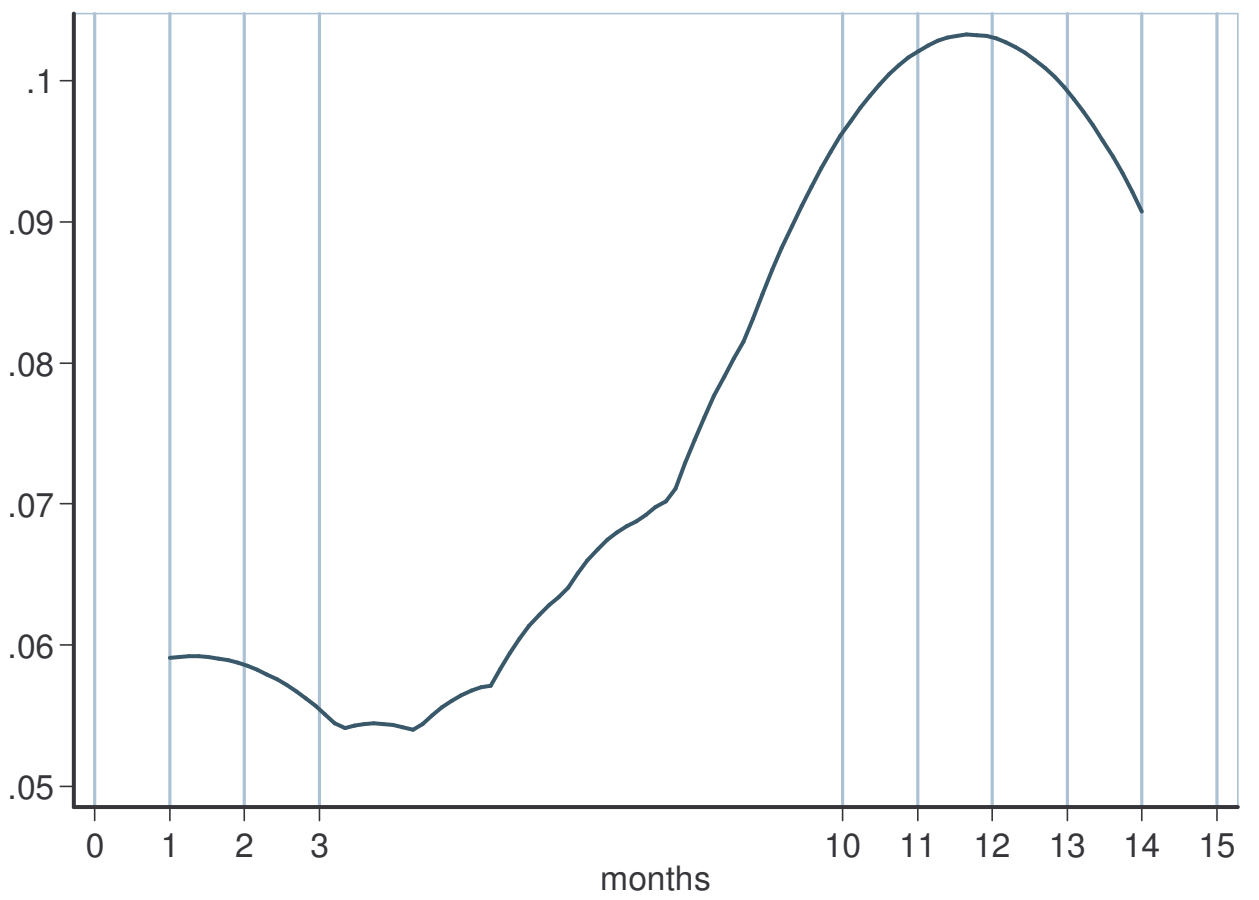

Source: Own elaboration based on PME 2002-2007.

\section{GRAPH 3}

Parameterized Probability (Hazard) Functions of Exiting Poverty

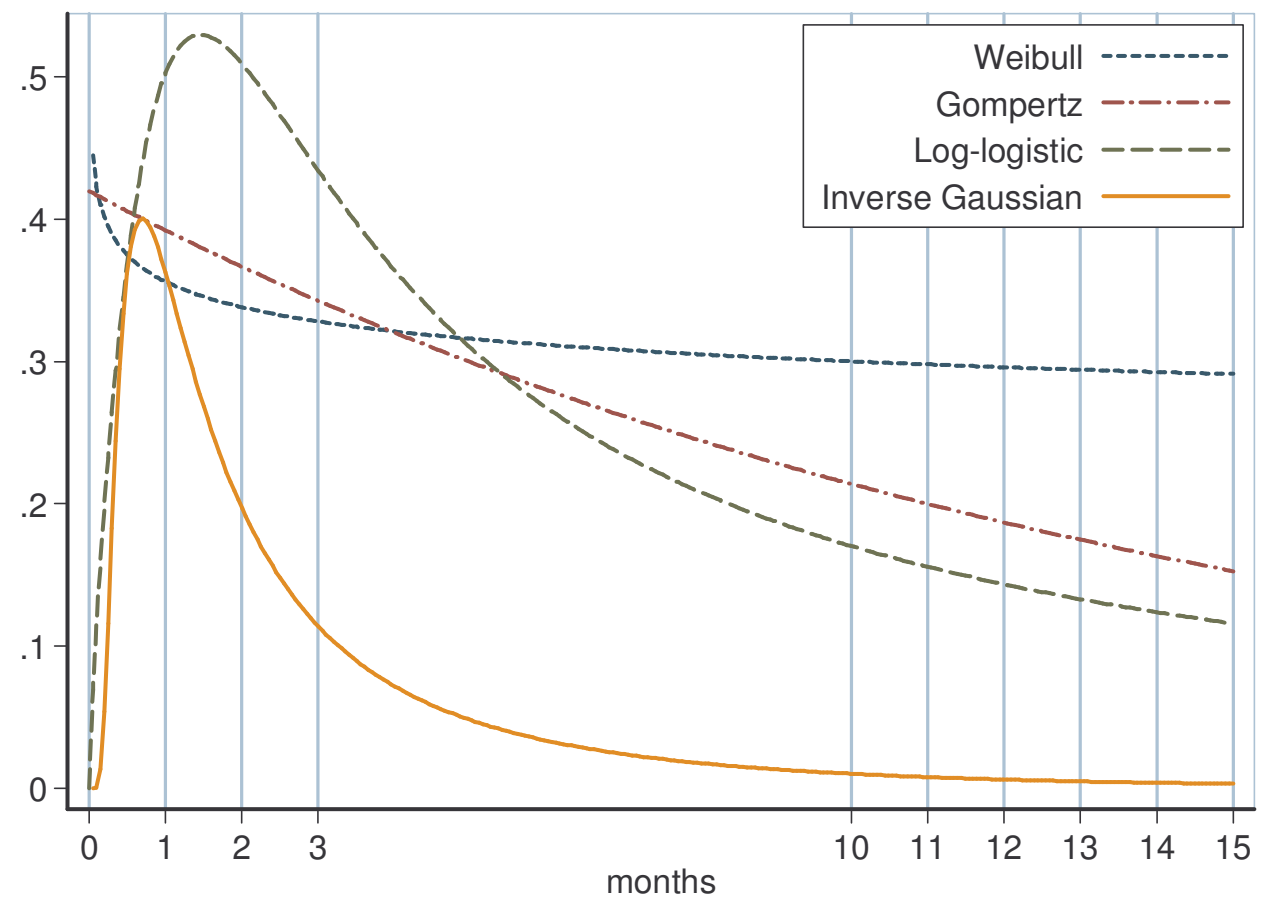


In order to verify whether the format of the hazard functions is heterogeneous according to the Wiener process, we tested the hypothesis that the parameter $c$ in function (2) is constant. The chi-square statistics of the Hausman test (13362.29 with 25 d.f.) indicates that the estimation of the Wiener process with absorption is more consistent than a simple estimation of an inverse Gaussian model. The estimated determinants of the distance between the starting and the absorption points are given in Annex (Table A2).

Graph 4 illustrates three mean hazard functions estimated according to the Wiener process - one with the minimum value of $c$ found in the sample, which is equal to 1.11; another with the sample mean value of $c$ equal to 1.48; and a third with the maximum value of $c$ found in the sample, which is equal to 2.6. Thus, there are households with a higher probability of leaving poverty immediately in the first month, just as there are households that, having fallen into poverty, are already subject to remaining in this situation for a long time. However, in spite of the value of c obtained, the hazard functions always show a negative slope from the second month onwards.

\section{GRAPH 4}

\section{Probability Functions of Exiting Poverty Estimated Based on the Wiener Process with Absorption}

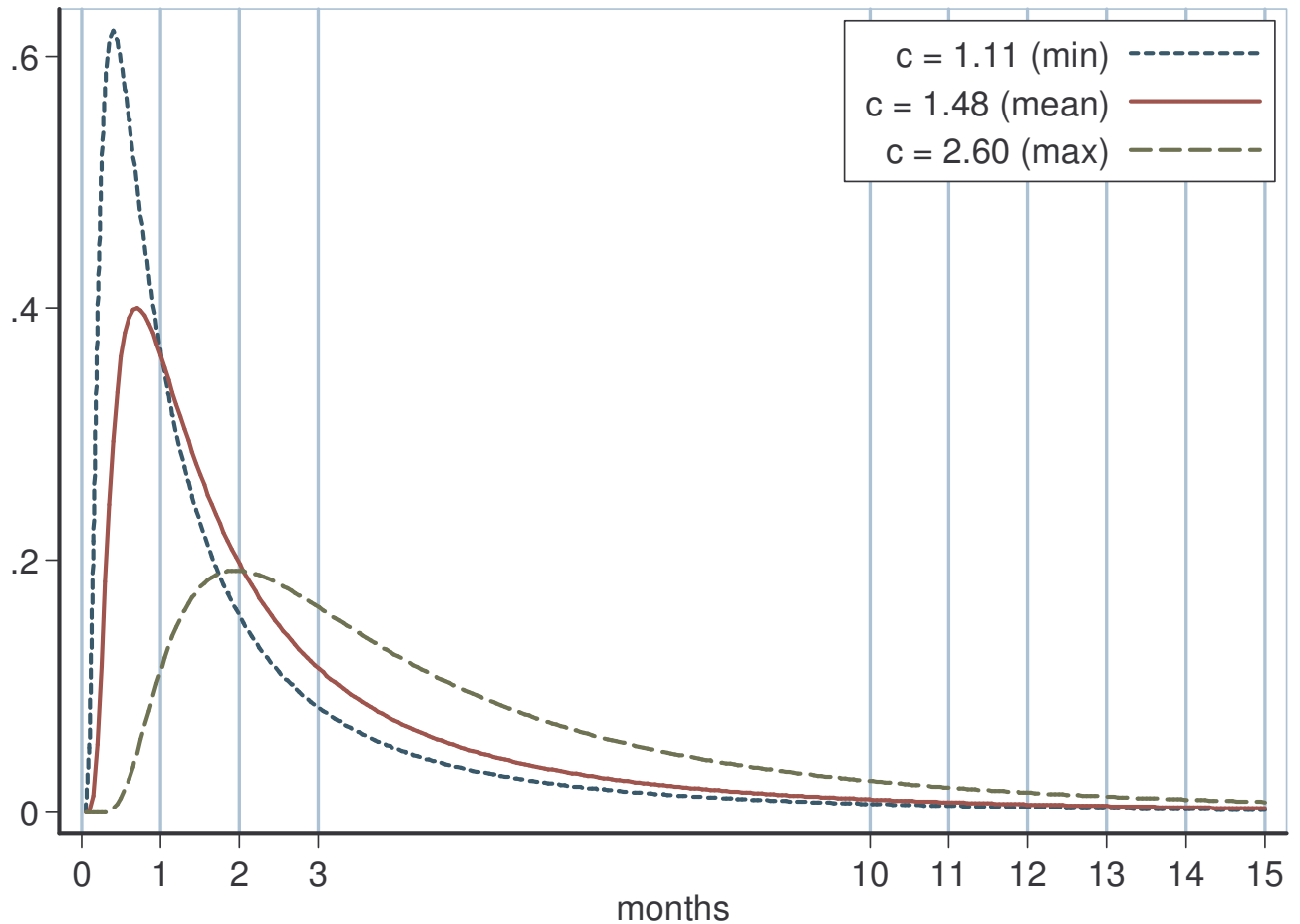

Source: Own elaboration based on PME 2002-2007.

\subsection{THE DETERMINANTS OF LEAVING POVERTY}

Table 3 gives the results of the hazard function, estimated by assuming the Weibull, Gompertz, Log-logistic and inverse Gaussian (Wiener process with absorption) distributions. The regressions presented in this table estimate the effects of the household's fixed characteristics, obtained during the first month that it was observed in poverty. In addition 
to the regression coefficients, the table provides for each covariate the odds ratio of the Log-logistic model and the hazard ratio for the other models.

In the regressions, almost all of the coefficients are significant. The exceptions are the coefficients related to the dummy variables for unmarried household head and unmarried female head. The following household characteristics reduce the probability of remaining in poverty: 1) an extended household, ${ }^{8} 2$ ) most members are working-age adults, and 3) the presence of adults with a higher level of schooling. The effects of having mostly working-age members and having adults with a higher level of schooling are indirect indications of the positive role played by labour supply on the probability of exiting poverty.

TABLE 3

Regressions Results for Different Duration Models

\begin{tabular}{|c|c|c|c|c|c|c|c|c|c|c|c|c|}
\hline & \multicolumn{3}{|c|}{ Weibull } & \multicolumn{3}{|c|}{ Gompertz } & \multicolumn{3}{|c|}{ Log-logistic } & \multicolumn{3}{|c|}{ Inverse Gaussian } \\
\hline & hazard ratio & coef. & & hazard ratio & coef. & & odds ratio & coef. & & hazard ratio & coef. & \\
\hline MA Salvador & 0.96763 & -0.03290 & ** & 0.96360 & -0.03708 & $* * *$ & 0.83375 & -0.18182 & $* * *$ & 1.07912 & 0.07614 & $* * *$ \\
\hline MA Belo Horizonte & 1.27206 & 0.24064 & $* * *$ & 1.24222 & 0.21690 & $* * *$ & 1.39104 & 0.33005 & *** & 1.33586 & 0.28958 & *** \\
\hline MA Rio de Janeiro & 1.08136 & 0.07822 & $* * *$ & 1.07189 & 0.06942 & $* * *$ & 1.06876 & 0.06650 & *** & 1.14468 & 0.13513 & *** \\
\hline MA São Paulo & 1.18567 & 0.17031 & $* * *$ & 1.16088 & 0.14918 & $\star * *$ & 1.21272 & 0.19287 & $* * *$ & 1.26489 & 0.23499 & $* * *$ \\
\hline MA Porto Alegre & 1.29204 & 0.25623 & $* * *$ & 1.25987 & 0.23101 & $* * *$ & 1.41824 & 0.34942 & $* * *$ & 1.33342 & 0.28774 & *** \\
\hline Log of the number of members & 0.83593 & -0.17921 & $* * *$ & 0.85443 & -0.15732 & $* * *$ & 0.75071 & -0.28673 & $* * *$ & 0.87353 & -0.13521 & $* * *$ \\
\hline Extended Household & 1.05662 & 0.05507 & $* *$ & 1.04486 & 0.04388 & $* *$ & 1.11531 & 0.10914 & $* * *$ & 1.02957 & 0.02914 & \\
\hline More than $50 \%$ are working-age & 1.15022 & 0.13995 & $* * *$ & 1.13267 & 0.12458 & $* * *$ & 1.32071 & 0.27817 & *** & 0.86382 & -0.14639 & * \\
\hline \multicolumn{13}{|l|}{ Presence of: } \\
\hline one child or more & 0.91890 & -0.08458 & $* * *$ & 0.92279 & -0.08035 & $* * *$ & 0.90982 & -0.09451 & *** & 0.80215 & -0.22045 & $* * *$ \\
\hline two children or more & 0.84166 & -0.17238 & $\star * \star$ & 0.85921 & -0.15174 & $* * *$ & 0.69786 & -0.35974 & $* * *$ & 0.86685 & -0.14289 & *** \\
\hline one adolescent or more & 0.90879 & -0.09564 & $* * *$ & 0.91596 & -0.08779 & $\star * *$ & 0.88906 & -0.11759 & *** & 0.79000 & -0.23572 & $* * *$ \\
\hline two adolescents or more & 0.96938 & -0.03110 & * & 0.96953 & -0.03095 & ** & 0.98155 & -0.01862 & & 0.85019 & -0.16230 & $* * *$ \\
\hline one elderly person or more & 1.22268 & 0.20104 & $\star \star *$ & 1.20752 & 0.18857 & $\star \star *$ & 1.34476 & 0.29622 & *** & 1.26400 & 0.23428 & *** \\
\hline illiterate adult & 0.96902 & -0.03147 & * & 0.97080 & -0.02963 & * & 0.97103 & -0.02940 & & 0.91253 & -0.09153 & ** \\
\hline functionally illiterate adult & 0.97031 & -0.03014 & ** & 0.97348 & -0.02688 & ** & 0.94976 & -0.05155 & *** & 0.98057 & -0.01962 & \\
\hline adult with elementary education & 1.05944 & 0.05774 & $* * *$ & 1.05208 & 0.05077 & $\star * *$ & 1.12079 & 0.11403 & $* * *$ & 0.99574 & -0.00427 & \\
\hline $\begin{array}{l}\text { at least two adults with } \\
\text { elementary education }\end{array}$ & 1.10257 & 0.09764 & $* * *$ & 1.08950 & 0.08572 & $\star * *$ & 1.15790 & 0.14661 & *** & 1.11930 & 0.11271 & *** \\
\hline adult with high school & 1.08563 & 0.08216 & $* * *$ & 1.07620 & 0.07344 & $\star * *$ & 1.13326 & 0.12510 & *** & 1.09389 & 0.08974 & *** \\
\hline adult with college education & 1.16096 & 0.14925 & $* * *$ & 1.15513 & 0.14422 & $\star * *$ & 1.16266 & 0.15071 & $* * *$ & 1.30038 & 0.26266 & *** \\
\hline White head & 1.02680 & 0.02645 & ** & 1.02633 & 0.02599 & $* *$ & 1.05845 & 0.05680 & $* * *$ & 1.00624 & 0.00622 & \\
\hline Unmarried head & 0.98227 & -0.01789 & & 0.98243 & -0.01773 & & 0.99889 & -0.00111 & & 0.92823 & -0.07448 & \\
\hline Unmarried female head & 0.99631 & -0.00369 & & 0.99535 & -0.00466 & & 0.99188 & -0.00815 & & 0.93741 & -0.06463 & \\
\hline Head's age & 1.01094 & 0.01256 & $* * *$ & 1.01014 & 0.01152 & $\star * *$ & 1.01828 & 0.03282 & *** & 1.01515 & 0.01706 & $* * *$ \\
\hline Head's age squared & & -0.00002 & & & -0.00002 & & & -0.00016 & $* * *$ & & -0.00002 & \\
\hline Poverty income gap & 0.78376 & -0.84113 & $* * *$ & 0.80403 & -0.75411 & $* * *$ & 0.61997 & -1.55680 & *** & 0.93260 & -0.46405 & $* * *$ \\
\hline Poverty income gap squared & & 0.58418 & $\star \star *$ & & 0.52406 & $\star \star *$ & & 1.05472 & *** & & 0.38550 & *** \\
\hline Constant & & -1.29955 & $* * *$ & & -1.18945 & $\star \star *$ & & -1.70628 & *** & & -1.08123 & $* * *$ \\
\hline $\begin{array}{l}\text { Parameter of the hazard } \\
\text { Function }\end{array}$ & $p$ & 0.92549 & $* * *$ & gamma & -0.06742 & $\star * *$ & gamma & 0.56365 & $* * *$ & $c^{1}$ & 1.45594 & \\
\hline
\end{tabular}

Note: 1 . This value represents the mean of the sample since it was parameterized according to some of the covariates. The coefficients of the regression of the logarithm of $c$ can be found in the Annex. ${ }^{*}$ means significant at $5 \% ;{ }^{* *}$ significant at $1 \%$; ${ }^{* * *}$ significant at $0.1 \%$; and MA $=$ Metropolitan Area.

Source: Own calculations based on PME 2002-2007. 
The probability of exiting poverty is even greater the older the household head. Nonetheless, the presence of an elderly member in the household is more important than all other characteristics. This factor increases the chances of leaving poverty by more than 20 per cent. The reason for this might be the effect of retirement benefits on providing extra income for poor households. That is, the pensions paid to these elderly members probably contribute to reducing the depty of poverty (the poverty income gap), thus making it easier for these households to exit poverty when another member obtains additional income.

The factors that contribute to a longer permanence in poverty are as follows: a higher number of household members; the presence of children and adolescents; and the presence of illiterate adults. In addition, there is a higher probability that households will remain in poverty if the head is non-White. This difference might be the result, among other factors, of the wellknown fact that Blacks suffer from discrimination in the Brazilian labour market.

In general, many of these results were expected. However, the use of the poverty income gap (i.e., the depth of poverty) as a covariate in the duration model leads to new results. In fact, the greater the distance of household per capita income below the poverty line, the lower the probability of moving out of poverty. But this effect is significantly convex. Graph 5 presents the estimated hazard ratio according to the poverty income gap. This graph shows that the households that entered into poverty with zero income (namely, the gap is equal to one) are not the ones with the lowest probability of exiting from this condition. That is, the households that currently are most poverty-stricken are not the most chronically poor.

\section{GRAPH 5}

\section{Effect of the Initial Poverty Income Gap on the Probability of Exiting Poverty}
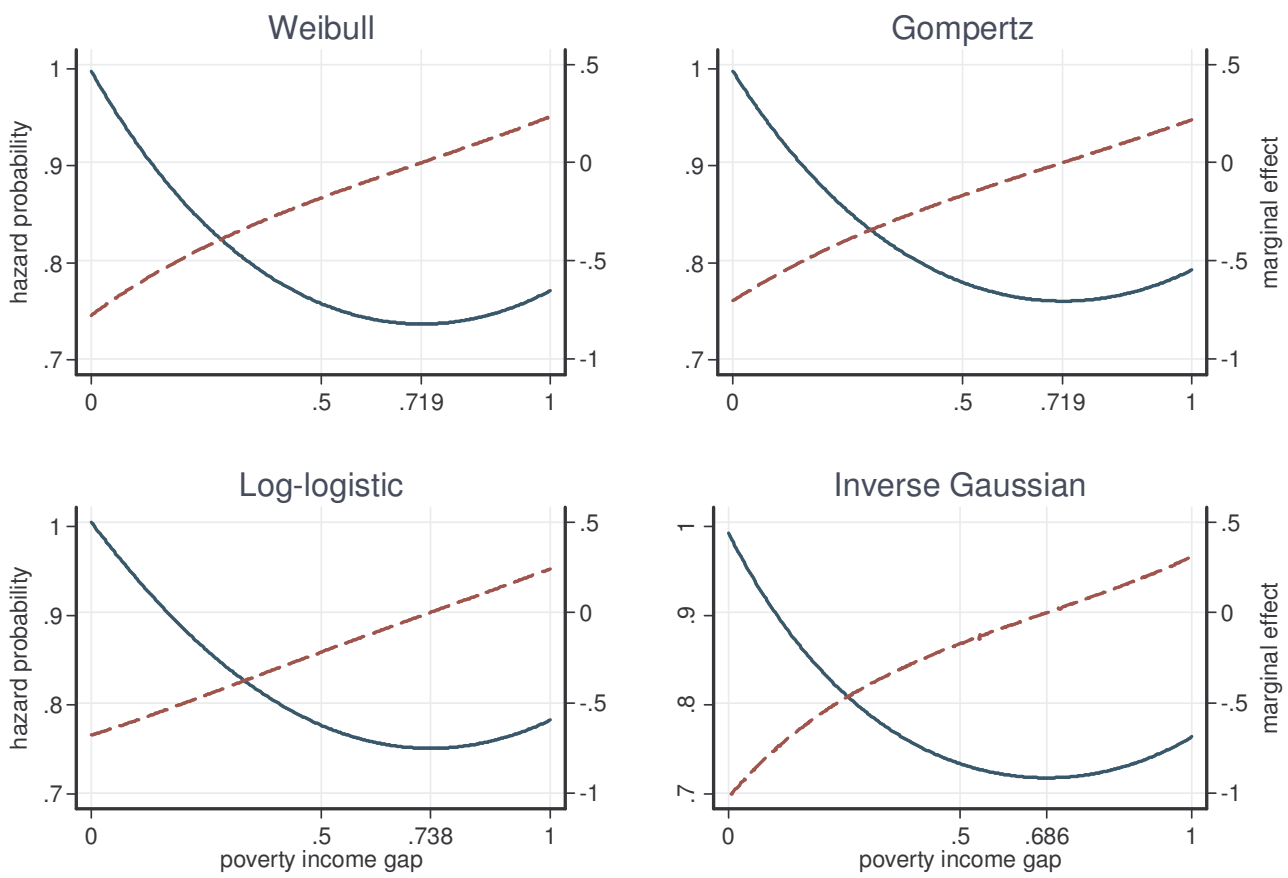

solid line = hazard probability; dash line = marginal effect 
The households with a poverty income gap equal to one are probably the ones that lost temporarily their only source of income because, for example, the household head became unemployed. Nevertheless, such households have a greater chance of exiting poverty when the head or another working-age member of the household finds a new job than the households that have not undergone this change but continue to receive a low level of income that is insufficient to sustain their members.

\subsection{THE EFFECT OF LABOUR MARKET CHANGES ON EXITING POVERTY}

Inspired mainly by the work of Iceland (1977b), we constructed time-varying covariates that represent changes in the labour market in order to estimate the effects of aggregate demand on poverty duration. Specifically, we analyzed the effects of quarterly variations in 1) the proportions of employees in the sectors of industry, commerce and construction in relation to the service sector; 2 ) in the unemployment rate, and 3 ) in the average real wage of civil servants, the self-employed, and registered and unregistered employees.

Table 4 describes the magnitude of these variations during a period of 60 months (from June 2002 to May 2007) in the six previously mentioned metropolitan areas. It shows that, in spite of the averages being close to zero, the deviations are large enough to make it possible to analyze the impact of these changes.

TABLE 4

Descriptive Statistics of Aggregate Changes

\begin{tabular}{lcccc}
\hline Variation (\%) in & Mean & Standard Deviation & Minimum & Maximum \\
\hline Average wage of all employees & -0.1146 & 3.5527 & -16.5691 & 12.1042 \\
Average wage of self-employed workers & -0.3332 & 7.3220 & -32.4074 & 22.8641 \\
Average wage of registered employees & -0.0255 & 3.6118 & -12.8106 & 13.3582 \\
Average wage of unregistered employees & 1.2207 & 3.3574 & -11.2621 & 15.2554 \\
Average wage of civil servants & 0.2407 & 5.7320 & -18.4483 & 20.2215 \\
Unemployment rate & -0.2946 & 10.0339 & -26.1539 & 39.5833 \\
Proportion of employees in industry & -0.0479 & 4.3228 & -17.1920 & 18.2049 \\
Proportion of employees in construction & 0.1114 & 6.5141 & -17.8042 & 25.7944 \\
Proportion of employees in commerce & -0.2843 & 3.8151 & -14.5585 & 10.4305 \\
\hline Number of Metropolitan Areas & 6 & & & \\
Number of months & 60 & & & \\
Total observations & 360 & & & \\
\hline
\end{tabular}

Source: PME 2002-2007.

Of all these changes in the labour market, the only factor that shows a clear rising trend during the period is the average wage of workers who are not officially registered; the average growth rate of their wage is 1.22 per cent per quarter. The greatest variability is observed in the unemployment rate, which has a standard deviation of 10 per cent in relation to the average percentage variation. That is to say, the unemployment rate is the aggregate indicator with the highest fluctuation around its trend. Next in line comes the average earnings of those who are self-employed (standard deviation of 7.3 per cent), 
followed by the proportion of workers in the construction sector (standard deviation of 6.5 per cent). The average income of civil servants also shows a relatively high degree of variability, with a standard deviation of 6.5 per cent.

In order to include these covariates, which change over time, in the estimation of the duration model, we had to expand (split) the sample, including for each household all the months in which it was interviewed and was in poverty. The consequence of this expansion on the sample has already been shown in Table 2. The results of the estimated probability of exiting poverty for this new sample are shown in Table 5.

All of the models use the households' fixed covariates and include time-varying covariates in stages. The first model considers only the fluctuations in all employees' average wage. The second model specifies the variation in average income according to occupation. The third model includes the variation in the unemployment rate. And the fourth model includes the variations in the proportion of employees by sector. The last, and most complete, model incorporates dummy variables for months to control for seasonality. ${ }^{9}$

According to the coefficients that were estimated, we found that a quarterly increase of one per cent in average earnings actually reduces the probability of exiting poverty between 0.6 and 0.9 per cent. A possible explanation for this result is that the rise in the average wage causes an increase in the labour supply of more skilled workers and that this, in turn, creates greater difficulties for the insertion of less skilled workers in the formal labour market. In other words, the consequence of the rising average wage might be the rise in the unemployment rate for workers with low qualifications.

Decomposing this effect by the type of occupation, we find that a quarterly increase of one per cent in the average income of registered workers actually reduces the probability of exiting poverty by 5 to 9 per cent. But the same growth in the earnings of unregistered workers increases this probability by 6 to 12 per cent. According to Machado, Ribas and Penido (2007), poor workers are concentrated in the informal sector in Brazilian metropolitan areas. Thus, one can assume that the latter effect tends to increase the income in poor households, whereas the former effect leads to a lower participation of poor workers in the labour market, mainly in the formal sector.

Table 5 shows that, fortunately for poor households, earnings in the informal sector have been increasing more quickly, on average, than in the formal sector. Part of this growth can be attributed to the re-adjustments in the minimum wage. As Giambiagi and Franco (2007) ${ }^{10}$ note well, the so-called 'light-house' effect of the minimum wage has a substantial impact on the informal labour market. The employer who does not officially register workers is not forced to readjust their wages because he is already acting illegally. However, moral considerations (the need to obey social norms) and/or the practical necessity to avoid worker dissatisfaction can lead the employer to follow the law regarding the minimum wage, even if this is done in an informal manner. This behaviour tends to be more common in metropolitan areas because of the greater number of labour unions.

When there is no control for seasonality, we found that the direct effect of reducing the unemployment rate by one per cent on the probability of exiting poverty is only 0.3 per cent. When seasonality is controlled, this effect is no longer significant. Therefore, the unemployment rate, in itself, does not affect a household's permanence in poverty. Nevertheless, the effect of unemployment on permanence in poverty takes place indirectly through several channels, especially through the seasonality of economic activity and the rise or fall in the amount of earnings in the economy. 
TABLE 5

Effects of Aggregate Changes Estimated Using Different Models of Poverty Duration

\begin{tabular}{|c|c|c|c|c|c|}
\hline & (1) & $(2)$ & (3) & $(4)$ & (5) \\
\hline Effect of quarterly variation on: & \multicolumn{5}{|c|}{ Weibull model - hazard ratio } \\
\hline average wage of all employees & $0.9925^{* * *}$ & & & & \\
\hline average wage of self-employed workers & & $0.9984^{* * *}$ & $0.9983^{* * *}$ & 0.9989 ** & $0.9976^{* * *}$ \\
\hline average wage of registered employees & & $1.0707^{* * *}$ & $1.0726 * * *$ & $1.0777^{* * *}$ & $1.0988^{* * *}$ \\
\hline average wage of unregistered employees & & $0.9386^{* * *}$ & $0.9379 * * *$ & $0.9329 * * *$ & $0.9183^{* * *}$ \\
\hline average wage of civil servants & & $0.9983^{* * *}$ & $0.9982 * * *$ & 0.9990 * & $0.9982^{* * *}$ \\
\hline unemployment rate & & & $0.9973^{* * *}$ & 0.9972 *** & 1.0001 \\
\hline proportion of employees in industry & & & & $0.9945^{* * *}$ & $0.9932 * * *$ \\
\hline proportion of employees in construction & & & & 0.9995 & 1.0004 \\
\hline proportion of employees in commerce & & & & $0.9888^{* * *}$ & $0.9908^{* * *}$ \\
\hline Effect of quarterly variation on: & \multicolumn{5}{|c|}{ Gompertz model - hazard ratio } \\
\hline average wage of all employees & 0.9939 *** & & & & \\
\hline average wage of self-employed workers & & 0.9986 *** & 0.9986 *** & 0.9991 * & $0.9980^{* * *}$ \\
\hline average wage of registered employees & & $1.0585^{* * *}$ & $1.0600 * * *$ & $1.0645^{* * *}$ & 1.0822 *** \\
\hline average wage of unregistered employees & & $0.9490 * * *$ & $0.9485^{* * *}$ & $0.9440 * * *$ & $0.9314^{* * *}$ \\
\hline average wage of civil servants & & $0.9984^{* * *}$ & $0.9984^{* * *}$ & 0.9990 * & $0.9984^{* * *}$ \\
\hline unemployment rate & & & 0.9976 *** & $0.9975^{* * *}$ & 1.0001 \\
\hline proportion of employees in industry & & & & $0.9953^{* * *}$ & $0.9941^{* * *}$ \\
\hline proportion of employees in construction & & & & 0.9994 & 1.0002 \\
\hline proportion of employees in commerce & & & & $0.9901^{* * *}$ & $0.9919^{* * *}$ \\
\hline Effect of quarterly variation on: & \multicolumn{5}{|c|}{ Log-logistic model - odds ratio } \\
\hline average wage of all employees & $0.9937^{* \star *}$ & & & & \\
\hline average wage of self-employed workers & & $0.9980 * * *$ & $0.9980 * * *$ & 0.9988 * & $0.9976^{* * *}$ \\
\hline average wage of registered employees & & 1.0619 *** & 1.0632 *** & $1.0688^{* * *}$ & $1.0887^{* * *}$ \\
\hline average wage of unregistered employees & & $0.9481^{* * *}$ & $0.9478^{* * *}$ & $0.9421^{* * *}$ & $0.9280 * * *$ \\
\hline average wage of civil servants & & 0.9972 *** & $0.9971 * * *$ & 0.9980 ** & $0.9970^{* * *}$ \\
\hline unemployment rate & & & $0.9973^{* * *}$ & $0.9971^{* * *}$ & 1.0008 \\
\hline proportion of employees in industry & & & & $0.9949 * * *$ & $0.9936 * * *$ \\
\hline proportion of employees in construction & & & & $0.9983 * *$ & 0.9993 \\
\hline proportion of employees in commerce & & & & $0.9871^{* * *}$ & $0.9895^{* * *}$ \\
\hline Effect of quarterly variation on: & \multicolumn{5}{|c|}{ Inverse Gaussian model - hazard ratio } \\
\hline average wage of all employees & $0.9911^{* * *}$ & & & & \\
\hline average wage of self-employed workers & & 0.9989 & 0.9988 * & 0.9998 & $0.9976^{* * *}$ \\
\hline average wage of registered employees & & $1.0831 * * *$ & $1.0862 * * *$ & $1.0934 * * *$ & $1.1187^{* * *}$ \\
\hline average wage of unregistered employees & & $0.9291 * * *$ & $0.9279 * * *$ & $0.9212 * * *$ & $0.9049 * * *$ \\
\hline average wage of civil servants & & $0.9973^{* * *}$ & $0.9973^{* * *}$ & 0.9982 * & $0.9971^{* * *}$ \\
\hline unemployment rate & & & $0.9966 * * *$ & $0.9965^{* * *}$ & 0.9999 \\
\hline proportion of employees in industry & & & & $0.9927^{* * *}$ & $0.9913^{* * *}$ \\
\hline proportion of employees in construction & & & & 0.9996 & $1.0014 *$ \\
\hline proportion of employees in commerce & & & & $0.9852^{* * *}$ & $0.9874^{* * *}$ \\
\hline \multicolumn{6}{|l|}{ Control variables } \\
\hline Household fixed characteristics & $x$ & $X$ & $x$ & $x$ & $x$ \\
\hline Dummy for months of the year & & & & & $\mathrm{x}$ \\
\hline
\end{tabular}

Note: ${ }^{*}$ significant at $5 \%,{ }^{* *}$ significant at $1 \%,{ }^{* * *}$ significant at $0.1 \%$.

Source: Own calculations based on PME 2002-2007. 
With regard to the participation of employees by sector, we can see that the reduction of one per cent in the proportion of industrial and commercial workers in relation to servicesector workers increases the probability that households will leave poverty by around 0.5 to one per cent, respectively. That is to say, the movement of industrial and commercial workers into the service sector in metropolitan areas significantly reduces the period spent by households in poverty. However, according to Table 4, on average, this change has been taking place very slowly. As a final note, the effect of changes in the proportion of employees in the construction sector is not significant in most of the models analyzed.

\section{CONCLUSION}

This Working Paper seeks to calculate the probability of households moving out of poverty and identify the determinants of this event, taking into consideration the amount of time that households spend in this condition. The data that we analyzed, namely, those from the Monthly Employment Survey (PME, Pesquisa Mensal de Emprego), initially contained two limitations.

The first of these is related to the questionnaire, since it did not include questions about income from non-labour sources, such as retirement benefits and other pensions, unemployment insurance, interest and transfers from social programmes. This means that, if the PME were used in an unaltered form, it would underestimate household income and, consequently, overestimate poverty. To overcome this problem, we adopted the technique proposed by Elbers, Lanjouw and Lanjouw (2003) to impute household income not originating from work.

The second limitation of the panel that we used is the short interval during which households are observed. This drawback results in a high number of censored observations for the duration analysis. In order not to exclude both the right-censored cases, when the household is not observed escaping from poverty, and the left-censored cases, when the household's entry into poverty is not observed, we opted for the use of parametric survival models that control for the initial condition (i.e., the first observation of a household already in poverty). If censored observations were omitted from the analysis, we would introduce a strong bias into the results because we would be systematically excluding households in the middle of a long period in poverty.

In spite of this limitation in the period during which households are observed, we consider the PME panel to be ideal because it allows us to investigate short-term changes. The results of the parametric survival models suggest that the probability of moving out of poverty decreases, the longer the household has remained in poverty-mainly after the second month in this condition. Therefore, the longer the household stays in poverty, the greater the chances that it will remain there.

Among the household characteristics that have an effect on exiting poverty as opposed to staying in that condition, the presence of an elderly person has the greatest impact: it increases the chances of leaving poverty by more than 20 per cent. The retirement benefits received by the elderly probably play an essential role as complementary income for poor households.

With regard to households that have entered poverty, we found that, in general, the greater the distance of their initial per capita income below the poverty line, the lower the probability of their exit from poverty. However, the households that entered into poverty 
with no income are not the ones with the lowest chance of exiting this state. For some households, the transitory nature of unemployment of the household head or other key working members puts them in the situation where their poverty income gap might be large but the probability of remaining in poverty is actually lower than that for households that have somewhat higher incomes but their poverty-level income is long-lasting.

Finally, in terms of changes in the labour market, we found that the movement of industrial and commercial workers into the service sector in metropolitan areas has caused a significant reduction in the length of time that households spend in poverty. However, this movement has, on average, been taking place very slowly. In fact, this process of 'tertiarization' might be already beginning to wane. Another important result is that changes in the unemployment rate do not have a direct effect on the likelihood of households remaining in or exiting poverty.

In the regression analysis, we also showed that increasing the average wage of the workers who were registered caused a significant reduction in the probability of the exit of poor households from poverty, whereas the increase of the average earnings of unregistered workers raised this probability to a significant degree. Indeed, poor workers are more concentrated in the informal than in the formal sector of the economy. Therefore, the increase in the average earnings of informal workers has the effect of increasing the income of poor households, while an increase in the wage of the rest of the formal-sector workers does not have the same effect.

We should take into account that, in Brazil, there is an enormous contingent of adults who face a huge difficulty in participating in the labour force, especially in the formal sector of the economy. For this group, job creation programmes could be ineffective in helping them exit poverty. In addition, increases in the average wage among formal-sector workers might make the participation of poor workers in the labour market even more difficult. Thus, the common strategy adopted by such workers in order to mitigate their conditions is to take up employment in informal low-paid jobs.

Therefore, we conclude that poverty reduction policies should go beyond the labour market and should reach out to the most chronically poor, instead of waiting for them to find a job and, as a result, move out of poverty in the short or medium term. An important point in this regard is to create economic conditions in which they can support themselves in a dignified manner and are able to overcome their disadvantages in the long term by obtaining better education and greater skills. In the short run, real increases in the minimum wage could offer a solution, since such increases have a positive effect on the earnings of lower-skilled workers. 


\section{APPENDIX I}

\section{IMPUTATION METHOD FOR NON-LABOUR INCOME}

In the first step of the imputation models, we estimated the probability that each household (or individual) would receive income from sources other than labour, according to its (or his) characteristics $Z_{i}$. Therefore, using PNAD, we estimated the following probability equation:

$$
p_{k, i}^{*}=Z_{i}^{\prime} \gamma_{k}+r_{k, i}
$$

where $\gamma_{k}$ is the vector of coefficients, $r_{k, i}$ is the random term with zero mean and standard deviation equal to one, and $p_{k, i}^{*}$ is the latent variable that represents the household's (or individual's) propensity to receive income from source $k$, so that:

if $p_{k, i}^{*}>0$, that is, $r_{k, i}>-Z_{i}^{\prime} \gamma_{k}, p_{k, i}=1$, indicating that the unit $i$ receives income from source $k$; and

if $p_{k, i}^{*} \leq 0$, that is, $r_{k, i} \leq-Z_{i}^{\prime} \gamma_{k}, p_{k, i}=0$, indicating that the unit $i$ does not receive income from source $k$.

Using the estimation of equation (A1) by means of a probit model, we obtained a consistent estimator for the vector of coefficients, $\hat{\gamma}_{k}$. This estimator, combined with the simulated residual $\hat{r}_{k, i} \sim N(0,1)$ and the vector $Z_{i}$, reproduces in the PME data statistics that are very close to the proportion of households that receive income from other sources in the PNAD (see Table A1). If $\hat{r}_{k, i}>-Z_{i}^{\prime} \hat{\gamma}_{k}$, we generate the variable $\hat{p}_{k, i}=1$, which indicates that the unit $i$ will have income $k$ imputed to it. Otherwise, we create the variable $\hat{p}_{k, i}=0$, indicating that the unit $i$ does not have income $k$ attributed to it.

We used a wide set of variables that is common to both databases, and defined the households and persons that would have income imputed to them in the PME. Then, the second step consists in estimating, using PNAD, the following equation:

$$
\ln \left(y_{k, i}\right)=X_{i}^{\prime} \beta_{k}+\xi_{k, i},
$$

where $y_{k, i}$ is the value of income $k, \beta_{k}$ is the vector of coefficients, $X_{i}$ is a subset of variables contained in $Z_{i}$, and $\xi_{k, i}$ is the sum of $\rho_{k} \lambda_{k, i}$ and the random error $e_{k, i}$ which has a zero mean and a standard deviation equal to $\sigma_{k, i} . \lambda_{k, i}=\phi\left(Z_{i}^{\prime} \gamma_{k}\right) / \Phi\left(Z_{i}^{\prime} \gamma_{k}\right)$ is the inverse Mills' ratio estimated on the basis of equation (A1), while $\rho_{k}$ is the parameter that represents the correlation between the residuals of equations (A1) and (A2).

Assuming that the residual $e_{k, i}$ has a heteroscedastic distribution, the values of $\sigma_{k, i}$ are also estimated by means of an equation:

$$
\ln \left(\frac{e_{k, i}^{2}}{A-e_{k, i}^{2}}\right)=W_{i}^{\prime} \alpha_{k}+\varepsilon_{k, i}
$$


where $\alpha_{k}$ is a vector of coefficients, $W_{i}$ is a vector of the explanatory variables, $\varepsilon_{k, i}$ is a homoscedastic residual and $A$ is the maximum limit of the predicted variance, which, according to Elbers, Lanjouw and Lanjouw (2003), is described as:

$$
A=1.05 * \max \left(e_{k, i}^{2}\right) \text {. }
$$

According to theses authors, using the parameters from equation (A3), the estimator of $\sigma_{k, i}$ is defined as:

$$
\hat{\sigma}_{k, i}=\sqrt{\left(\frac{A B}{1+B}\right)+\frac{1}{2} \operatorname{Var}\left(\varepsilon_{k, i}\right)\left[\frac{A B(1-B)}{1+B^{3}}\right]}
$$

where $B=\exp \left(W_{i}^{\prime} \hat{\alpha}_{k}\right)$.

The estimators $\hat{\beta}_{k}, \hat{\rho}_{k}$ and $\hat{\sigma}_{k, i}$ are calculated by using Ordinary Least Squares (OLS) on data from the PNAD. When they are combined with the set of characteristics $X_{i}$ and $W_{i}$, observed in the PME, and with the variable $\hat{\lambda}_{k, i}$, attributed in the first step of our procedure, these estimators determine the imputed value of income $k, \hat{y}_{k, i}$, for households or persons with $\hat{p}_{k, i}=1$. More specifically,

$$
\hat{y}_{k, i}= \begin{cases}\exp \left(X_{i}^{\prime} \hat{\beta}_{k}+\hat{\lambda}_{k, i} \hat{\rho}_{k}+\hat{e}_{k, i}\right) & \text { if } \hat{p}_{k, i}=1 \\ 0 & \text { if } \hat{p}_{k, i}=0\end{cases}
$$

where $\hat{e}_{k, i} \sim N\left[0, \hat{\sigma}_{k, i}\left(W_{i}\right)\right]$ is a simulated random error.

The sets of variables, $Z_{i}, X_{i}$ and $W_{i}$ were selected for each model estimated by means of a stepwise process. In the case of retirement benefits, the regressions in the PNAD and the respective imputations in the PME were made for the sample of individuals older than 30 years. The model of other pensions also took the sample of individuals into account but without imposing any age limit.

In order to calculate and impute the rest of the income, we used the household sample divided into two parts, namely, 'poorer households' and 'richer households', based on the sixth decile of the distribution of per capita labour incomes. The reason for this division is that up to the sixth decile, the relationship between the per capita value of other income and labour income is negative but becomes positive from then on. In addition to this factor, both the characteristics of these two groups and the sources of their other income are completely different.

Finally, we should point out some limitations of this imputation technique. The first refers to the maximum and minimum values of the imputed distributions. Some households in the PME contain values of income attributed outside the range observed in the PNAD. ${ }^{11}$ However, this difference does not signify any contradiction in the statistics in general. Another limitation is the fact that the income sources were estimated independently, that is, without taking the correlations between them into account. According to Table A1, this limitation also does not pose any problem for the statistics. 
The last limitation is that the income sources were attributed to the households or to persons independently in different months of the PME. The effect of this is merely residual, since the greater part of the non-labour income is explained by the observed variables. In any case, one way to overcome this limitation would be to attribute residuals that are valid for one single person or household for the whole panel and not just for one specific month. 


\section{ANNEX}

TABLE A1

Comparison between Household Income Statistics Observed in PNAD and Imputed to PME for September 2005

\begin{tabular}{|c|c|c|c|c|c|c|c|c|}
\hline & \multicolumn{4}{|c|}{ PNAD } & \multicolumn{4}{|c|}{ PME } \\
\hline & Mean & Median & $\begin{array}{l}\text { Standard } \\
\text { Deviation }\end{array}$ & $\begin{array}{c}\text { No. of } \\
\text { Observations }\end{array}$ & Mean & Median & $\begin{array}{l}\text { Standard } \\
\text { Deviation }\end{array}$ & $\begin{array}{c}\text { No. of } \\
\text { Observations }\end{array}$ \\
\hline Receive labour income & 0.83808 & 1 & 0.36838 & 31208 & 0.82196 & 1 & 0.38255 & 31099 \\
\hline Log of labour income & 6.95593 & 6.90776 & 0.98222 & 26185 & 6.93301 & 6.90776 & 0.95975 & 25557 \\
\hline Receive retirement benefit & 0.23989 & 0 & 0.42702 & 31856 & 0.26548 & 0 & 0.44160 & 31099 \\
\hline Receive other pensions & 0.16797 & 0 & 0.37385 & 31919 & 0.17640 & 0 & 0.38116 & 31099 \\
\hline \multirow{2}{*}{$\begin{array}{l}\text { Income from other pensions } \\
\text { Log of income from other } \\
\text { pensions }\end{array}$} & 658.79 & 345.00 & 877.77 & 5311 & 732.31 & 454.35 & 1062.92 & 5511 \\
\hline & 6.09417 & 5.84354 & 0.82815 & 5311 & 6.15991 & 6.11887 & 0.89900 & 5511 \\
\hline Receive other earnings & 0.13687 & 0 & 0.34371 & 31871 & 0.13858 & 0 & 0.34551 & 31099 \\
\hline Value of other earnings & 542.15 & 220.00 & 1297.18 & 5061 & 698.09 & 206.10 & 2707.66 & 4913 \\
\hline Log of total non-labour income & 6.28806 & 6.39693 & 1.18821 & 14913 & 6.42064 & 6.49866 & 1.24591 & 14418 \\
\hline Total household income & 1948.03 & 1100.00 & 2809.86 & 31018 & 1955.28 & 1100.00 & 3011.90 & 31099 \\
\hline Log of household income & 7.07842 & 7.00307 & 0.97011 & 30595 & 7.10548 & 7.04780 & 0.97524 & 29903 \\
\hline Household size & 3.25804 & 3 & 1.61439 & 31978 & 3.17694 & 3 & 1.58896 & 31099 \\
\hline \multirow{2}{*}{$\begin{array}{l}\text { Per capita household income } \\
\text { log per capita household } \\
\text { income }\end{array}$} & 742.63 & 380.00 & 1281.95 & 31018 & 752.89 & 388.18 & 1360.50 & 31099 \\
\hline & 6.02715 & 5.97041 & 1.03353 & 30595 & 6.06798 & 5.99147 & 1.04623 & 29903 \\
\hline
\end{tabular}

Source: Own calculations based on PME 2005 and PNAD 2005.

TABLE A2

Regression Coefficients of the Logarithm of $c$, according to the Wiener Process (Inverse Gaussian Distribution)

\begin{tabular}{|c|c|c|c|c|c|}
\hline \multirow{3}{*}{$\begin{array}{l}\text { MA Salvador } \\
\text { MA Belo Horizonte }\end{array}$} & \multicolumn{2}{|c|}{ Coefficient } & \multirow[b]{2}{*}{ Presence of: } & \multicolumn{2}{|l|}{ Coefficient } \\
\hline & 0.08115 & $* * *$ & & & \\
\hline & 0.01441 & & one child or more & -0.06239 & *** \\
\hline MA Rio de Janeiro & 0.02267 & * & two children or more & 0.06510 & *** \\
\hline MA São Paulo & 0.03430 & *** & one adolescent or more & -0.05283 & *** \\
\hline MA Porto Alegre & 0.01037 & & two adolescents or more & -0.06011 & *** \\
\hline Log of number of members & 0.03053 & * & one elderly person or more & 0.00428 & \\
\hline Extended household & -0.02513 & & illiterate adult & -0.04119 & *** \\
\hline More than $50 \%$ are working age & -0.17938 & $* * *$ & functionally illiterate adult & 0.00598 & \\
\hline White household head & -0.01299 & & adult with elementary school & -0.03335 & *** \\
\hline Unmarried household head & -0.03061 & & two adults with elementary school & -0.00366 & \\
\hline Unmarried female head & -0.01806 & & adult with high school & -0.00445 & \\
\hline Head's age & -0.00801 & $* * *$ & adult with college education & 0.08517 & *** \\
\hline Head's age squared & 0.00009 & $* * *$ & Poverty income gap & 0.26961 & *** \\
\hline Constant & 0.60491 & $* \star *$ & Poverty income gap squared & -0.15860 & *** \\
\hline
\end{tabular}

Note: * significant at $5 \% ;{ }^{* *}$ significant at $1 \%$; ${ }^{* *}$ significant at $0.1 \% ; \mathrm{MA}=$ Metropolitan Area.

Source: Own calculations based on PME 2002-2007. 


\section{REFERENCES}

Aalen, O. O. and H. K. Gjessing (2001). 'Understanding the Shape of the Hazard Rate: A Process Point of View'. Statistical Science 16 (1): 1-22.

Amemiya, T. (1999). 'A Note on Left Censoring'. In Pesaran, H., K. Lahiri, C. Hsiao, L.-F. Lee (eds.), Analysis of Panels and Limited Dependent Variable Models, Cambridge University Press, p. 7-22.

Bane, M. J. and D. Ellwood (1986). 'Slipping Into and Out of Poverty: The Dynamics of Spells'. Journal of Human Resources 21 (1): 1-23.

Barros, R. P., S. Cury and G. Ulyssea (2007). 'A Desigualdade de Renda no Brasil Encontra-se Subestimada? Uma Análise Comparativa com Base na PNAD, na POF e nas Contas Nacionais'. Texto para Discussão 1263, IPEA, Rio de Janeiro.

Barros, R. P., R. Mendonça and M. Neri (1995). 'Duration of Spell of Poverty'. Anais do IV Encontro Nacional de Estudos do Trabalho, ABET.

Beccaria, L. and R. Maurízio (2006). 'Factors associated to poverty mobility in Greater Buenos Aires'. XLI Reunión Annual de la AAEP, Salta, Argentina.

Bigsten, A. and A. Shimeles (2003). 'The Dynamics of Poverty in Ethiopia'. WIDER Conference on Inequality, Poverty and Human Well-being, Helsinki, Finland.

Cappellari, L. and S. P. Jenkins (2002). 'Who Stays Poor? Who Becomes Poor? Evidence from the British Household Panel Survey'. Economic Journal 112: C60-C67.

Corseuil, C. H. and M. N. Foguel (2002). 'Uma sugestão de deflatores para rendas obtidas a partir de algumas pesquisas domiciliares'. Texto para Discussão 897, IPEA, Rio de Janeiro.

D'Addio, A. C. and M. Rosholm (2002). 'Left Censoring in Duration Data: Theory and Applications'. Working Paper 2002-5, Department of Economics, University of Aarhus, Denmark.

Denisova, I. (2007). 'Entry to and Exit from Poverty in Russia: Evidence from Longitudinal Data'. CEFIR/NES Working Paper 98, New Economic School, Moscow.

Dmitri, S. (2000). 'Persistent Poverty in Russia'. Working Paper BSP/2000/037 E, New Economic School, Moscow.

Doksum, K. A. and A. Høyland (1992). 'Models for variable-stress accelerated life testing experiments based on Wiener processes and the inverse Gaussian distribution'. Technometrics 34 (1): 74-82.

Duncan, G. J. (1983). 'The Implications of Changing Family Composition for the Dynamic Analysis of Family Economic Well-Being'. In Atkinson, A. B. and F. A. Cowell, (eds.), Panel Data Analysis, London: London School of Economics, p. 203-239.

Duncan, G. J. and Rodgers, W. (1991). 'Has Children's Poverty Become More Persistent?' American Sociological Review 56 (4): 538-550.

Elbers, C., J. O. Lanjouw and P. Lanjouw (2003). 'Micro-Level Estimation of Poverty and Inequality'. Econometrica 71 (1): 355-364.

Giambiagi, F and S. Franco (2007). 'O Esgotamento do Papel do Salário Mínimo como mecanismo de Combate à Pobreza Extrema'. Texto para Discussão 1290, IPEA, Rio de Janeiro. 
Gritz, M. (1993). 'The Impact of Training on the Frequency and the Duration of Employment'. Journal of Econometrics 57 (1-3): 21-51.

Heckman, J. J. (1979). 'Sample Bias as a Specification Error'. Econometrica 47 (1): 153-161.

Hussain, M. A. (2002). 'Poverty Duration in Denmark'. Welfare Distribution Working Paper 28, Danish National Institute of Social Research.

Iceland, J. (1997a). 'The Dynamics of Poverty Spells and Issues of Left-Censoring'. PSC Research Report 97-378, University of Michigan.

Iceland, J. (1997b). 'Urban labor markets and individual transitions out of poverty'. Demography 34 (3): 429-441.

Iceland, J. (2003). 'Dynamics of Economic Well-Being: Poverty 1996-1999'. Current Population Reports, P70-91, U.S. Census Bureau.

Lancaster, T. (1982). 'Econometric Methods for the Duration of Unemployment'. Econometrica 47 (4): 939-956.

Machado, A. F., R. P. Ribas and M. Penido (2007). 'Mobilidade entre estados de pobreza e inserção no mercado de trabalho: uma análise para o Brasil Metropolitano em 2004'. Economia Aplicada 11 (2): 253-279.

McKernan, S.M. and C. Ratcliffe (2003). 'Events that Trigger Poverty Entries and Exits'. JCPR Working Paper 317, Joint Center for Poverty Research, Northwestern University and University of Chicago.

Ribas, R. P. and A. F. Machado (2007). 'Distinguishing Chronic Poverty from Transient Poverty in Brazil: developing a model for pseudo-panel data'. Working Paper 36, International Poverty Centre, UNDP.

Ribas, R. P. and S. D. Soares (2008). 'Sobre o Painel da Pesquisa Mensal de Emprego (PME) do IBGE'. Texto para Discussão, IPEA, Brasília, forthcoming.

Ridder, G. (1984). 'The distribution of Single Spell Duration Data'. In G.R. Neumann and N. C. Westergard-Nielsen (eds.), Studies in Labor Market Dynamics, New York: Springer, p. 45-73.

Rosholm, M. (2001). 'An Analysis of the Processes of Labour Market Exclusion and (Re-) Inclusion'. IZA Discussion Paper 332, Institute for the Study of Labor, Bonn.

Ruggles, P. and R. Williams (1987). 'Transitions In and Out of Poverty: New Data from the Survey of Income and Program Participation'. U.S. Department of Commerce, Bureau of the Census, n. 8716.

Stevens, A. H. (1994). 'The Dynamics of Poverty Spells: Updating Bane and Ellwood'. American Economic Review 84 (2): 34-37.

Stevens, A. H. (1999). 'Climbing Out of Poverty, Falling Back in: Measuring the Persistence of Poverty Over Multiple Spells'. Journal of Human Resources 34 (3): 557-588.

Tarozzi, A. and A. Deaton (2007). 'Using Census and Survey Data to Estimate Poverty and Inequality for Small Areas'. Department of Economics, Princeton University.

World Bank (2006). 'Brazil: Measuring Poverty Using Household Consumption'. Report 36358BR, Poverty Reduction and Economic Management Sector Unit. 


\section{NOTES}

1. For criticism of the Elbers, Lanjouw and Lanjouw (2003) method, see Tarozzi and Deaton (2007).

2. In any case, the covariates used in the earnings equations constitute a subset of the covariates used in the selection equations. Indeed, the omitted variables in the second step are not significant in the earnings regressions.

3. Available at <www.ipeadata.gov.br>.

4. The generalized Gamma distribution, which represents the general case of exponential, Weibull and Log-logistic distributions, was not taken into account because the maximum likelihood estimation of this model did not converge. 5. See Gritz (1993) and Rosholm (2001) as references.

6. D'Addio and Rosholm (2002) propose another likelihood function that produces more robust results. However, using this function requires retrospective data about events prior to the situation under analysis.

7. The poverty lines were deflated in accordance with the modified INPC proposed by Corseuil and Foguel (2002), which can be found at <www.ipeadata.org.br $>$.

8. In the case of the inverse Gaussian model, this coefficient is not significant, as well as those coefficients related to the presence of a functionally illiterate adult, an adult with elementary education and a White household head.

9. Unfortunately, at the time of writing, the IBGE had not yet revealed the series removing seasonality from aggregate variables. The reason is that the period of time for the new series of the PME is too short.

10. In fact, Giambiagi and Franco (2007) intend to demonstrate that minimum wage policies do not help in reducing extreme poverty in Brazil as a whole. However, our results point to a positive effect of this kind of policy on the exit of households from poverty in metropolitan areas.

11. One suggestion for correcting this distortion is to simulate the residuals using distributions truncated in the maximum and minimum values observed in PNAD. 


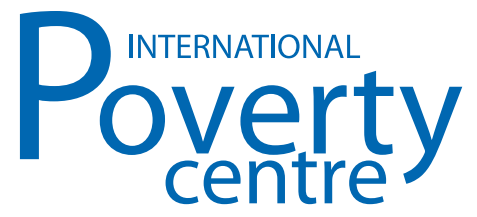

International Poverty Centre

SBS - Ed. BNDES $10^{\circ}$ andar

70076900 Brasilia DF

Brazil

povertycentre@undp-povertycentre.org

www.undp-povertycentre.org

Telephone +55 6121055000

Fax +55 6121055001 